\title{
CAUDAL EPIDURAL BLOCK FOR URETEROSCOPIC LITHOTRIPSY (URSL): A PROSPECTIVE STUDY
}

\author{
Bhattarai $R^{1^{*}}$, Paudel $B^{1}$, Subba $S^{2}$, Das $C R^{3}$
}

\begin{abstract}
Affiliation
1. Assistant Professor, Department of Anesthesiology, Nobel Medical College Teaching Hospital

2. Lecturer, Department of Anesthesiology, Nobel Medical College Teaching Hospital

3. Professor, Department of Anesthesiology, Nobel Medical College Teaching Hospital
\end{abstract}

\section{ARTICLE INFO}

Received : 26 January, 2020

Accepted : 18 March, 2020

Published : 30 June, 2020

(C) Authors retain copyright and grant the journal right of first publication with the work simultaneously licensed under Creative Commons Attribution License CC - BY 4.0 that allows others to share the work with an acknowledgment of the work's authorship and initial publication in this journal.

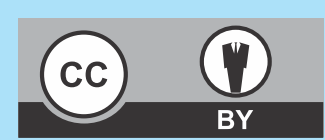

\section{ORA 161}

DOI: https://doi.org/10.3126/bjhs.v5i1.29630

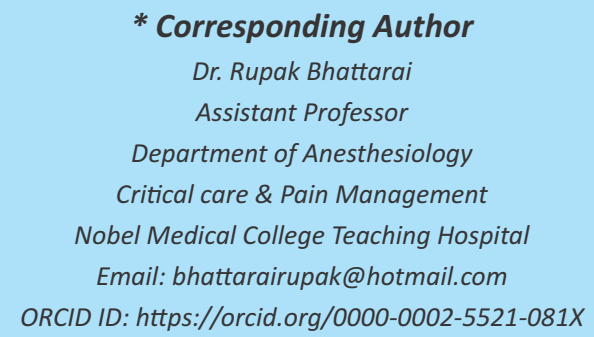

\section{Citation}

Bhattarai R, Paudel B, Subba S, Das CR. Caudal Epidural Block for Ureteroscopic Lithotripsy (URSL): A Prospective Study. BJHS 2020;5(1)11: 942-945.

\section{ABSTRACT \\ Introduction}

Ureteroscopic lithotripsy (URSL) is the surgical treatment of choice for ureter stones. There are lots of anesthetic considerations for removal of such stones. Generally, ureteroscopic lithotripsy are done under general anesthesia and spinal anesthesia.

\section{Objectives}

The purpose of this study is to assess whether ureteroscopic lithotripsy can be done under caudal anesthesia.

\section{Methodology}

This prospective observational study was conducted in Nobel Medical college Teaching hospital, Nepal over a period of one and half year from May 2018 to October 2019. All the 100 patients posted for ureteroscopic lithotripsy was given caudal anesthesia. Location of stone, duration of surgery, time of onset of caudal anesthesia, time and level of maximum block spread, Intensity of block was assessed .

\section{Result}

Out of 100 patients, 56 were male and 44 were female. The mean age and weight was $58 \pm 13.182$ and $62 \pm 18.42$ respectively. Time of onset of sensory block, 26 patients in 0 5 minutes, 26 patients in 5-10 minutes, 56 patients in 10-15 minutes, 12 patients in 15-20 minutes, 4 patients in 20-25 minutes \& 2 patients in more than 25 minutes. Maximum spread of block was seen at T6 level in 4 patients, at T8 level in 36 patients and at $\mathrm{T} 10$ level in 56 patients.

\section{Conclusion}

Caudal epidural block is a safe, effective anesthetic technique for ureteroscopic lithotripsy.

\section{KEYWORDS}

Anesthesia, caudal, spinal, ureter 


\section{INTRODUCTION}

The incidence of ureteric stone has increased tremendously in today's world. ${ }^{1}$ The compostion of ureteric stones includes Calcium oxalate monohydrate, Cystine, Uric acid etc. Majority of ureteric stones are made up of Calcium oxalate. Ureteroscopic Lithotripsy (URSL) is a common procedure done these days for removal of ureteric stones in eastern part of Nepal. As Ureteroscopic lithotripsy is popular these days due it's a minimal invasive, safe to use and high curative. Therefore, open surgery for ureteric stones has been gradually replaced by ureteroscopic lithotripsy. There are various methods of ureteroscopic lithotripsy which includes pneumatic, electrohydraulic and Holmium: YAG laser. In our hospital pneumatic type is the one and only method used to remove ureteric stone by ureteroscopic lithotripsy. It is most commonly done under general anesthesia or spinal anesthesia. ${ }^{2,3}$ However general anesthesia may risk the patients with stress response during inductions, post operative nausea and vomiting, respiratory complications and lithotomic related complications. Spinal anesthesia on the other hand may lead to more hemodynamic un-stability in already compromised morbid patients.

More recently, with the use of more advancement on the ureteroscopes and small caliber lithotripsy devices, the complications and pain associated with ureteroscopy have decreased to significant level and several studies has shown the effectiveness of Ureteroscopic lithotripsy even under a local anesthesia. ${ }^{4-7}$

Caudal epidural is more popular used in pediatric population but over the past 20 years its being used in older patients with therapeutic chronic pain management. ${ }^{8,9} \mathrm{Also}$, the recent literatures shows the renewed interest in the use of caudal approach to the epidural space in adults both instead of spinal or general anesthesia for urological and gynecological procedures as well as providing post operative pain management. ${ }^{10-12}$ Therefore, Caudal epidural block being widely popular as it is cheaper, easy to perform by an experienced anesthesiologist, less hemodynamic alterations and less postoperative pain. Moreover enough literature does-not exist till date about the role of using of caudal epidural block for URSL.

So, we plan to perform a ureteroscopic lithotripsy under caudal epidural block in patients with ureteric stones with the size less than $15 \mathrm{~mm}$.

\section{METHODOLOGY}

This study was conducted at Department of Anesthesiology, Critical Care and Pain Medicine, Nobel Medical College Teaching Hospital, Biratnagar, Nepal during the period of one and half year from May 2018 to October2019 after institutional review committee approval. This prospective observational study was carried out in 100 adult patients with ASA I, II, III and IV who were posted for Ureteroscopic Lithotripsy and willing to participate in our study. A convenient sample of 100 patients with inclusion criteria was taken for the study and thus data collected inserted in the pre made proforma which was later transferred to computer.

The inclusion criteria for this study was ASA I, II, III \& IV patients with age between $18-80$ years of age, stones lesser than $15 \mathrm{~mm}$ at ureter posted at Urology operation theatre with plan of ureteroscopic lithotripsy.

The exclusion criteria included Coagulopathies, stone sizes greater than $15 \mathrm{~mm}$, allergies to local anesthetics, Local or systemic infections, vertebral deformities, uncooperative patients and those patients who are not willing to participate in our study.

Pre-anesthetic checkup was done with all baseline investigations like $\mathrm{CBC}$, hemoglobin, renal functions test, Coagulation profiles, Urine routine examinations, X-ray KUB, Intravenous pyelography to find out the exact location of stones. HIV, HBAsg was done as a protocol of our hospital.

\section{Anesthetic Management}

After the written consent taken for surgery and anesthesia, all patients were pre-medicated with Tab. Lorazepam $1 \mathrm{mg}$ one night prior to surgery and on the day of surgery. After the patient bought to the operation theatre intravenous access was established with 18G large bore cannula on the non dominant hand. All the baseline monitors such as Heart Rate (HR), Non invasive blood pressure (NIBP), Pulse oximetry were attached and recorded as baseline hemodynamics.

\section{Caudal Anesthesia procedure:}

The patient were kept in prone position with a pillow placed under the iliac crest to correct lordosis and both legs abducted about 20 degree and toes turned inward. The sacral hiatus is identified firstly by palpating the triangular shaped gap at the posterior lowermost part of the sacrum bounded by the two sacral cornua. Secondly, it is confirmed again by palpating the posterior superior iliac spines and the line is drawn between them and equilateral triangle to apex of the triangle which coincide the sacral hiatus. Under strict aseptic technique a skin wheal is made over the sacral hiatus with $2 \%$ lignocaine as a local infiltration. With 20G,1.5" hypodermic blunt tipped needle was inserted through sacrococcygeal membrane at right angles to the skin surface. The needle was angled to 45 degree once pierced the membrane and advanced to the sacral canal in the midline at around $1.5 \mathrm{~cm}$ by loss of resistance technique. Once negative aspiration done for CSF and blood and negative for air crepitus in the subcutaneous tissue $25 \mathrm{ml}$ of local anesthetic solution of $1 \%$ preservative free lignocaine mixed with freshly prepared $125 \mathrm{mcg}$ of adrenaline so that the strength of adrenaline becomes 1:200000 was injected. After the injection, patients were made supine and oxygen at the flow of 4-6 litres/min was given by face mask. All patients were given bolus dose of Injection Midazolam according to body weight once the patients are kept supine. The baseline heart rate with systolic and diastolic blood pressure recorded and thereafter at $3 \mathrm{~min}, 5 \mathrm{~min}, 10 \mathrm{~min}$ and then every 10 minutes till the surgery ends. The stone size, 
location of stone and duration of surgery noted. Time of onset of caudal anesthesia, time and level of maximum block spread were noted, Intensity of block was assessed using Modified Bromage Scale. Nausea \& Vomiting if present treated with Injection Ondensatron $4 \mathrm{mg}$ intravenously. Duration of analgesia was assessed till regression of 2 segments noted. Complications if any recognized and treated accordingly.

The onset of analgesia was tested once the level of block reached $\mathrm{T} 10$, and then the patient is kept on lithotomy position for cystoscopy and for ureteroscopy. The total duration of Surgery and Anesthesia noted.

\section{Stastical Analysis:}

Data were expressed as mean \pm standard deviation, number and percentage. The findings of this study was done using SPSS version 12.

\section{RESULTS}

In our study, out of 100 patients taken for the study, 56 were male and 44 were female. In the present study, the age of patients ranged from 18 to 80 years of age, with the mean age of $58 \pm 13.182$. The mean weight of the patient in this study was $62 \pm 18.42$. Regarding, the height of the patients ranges from $150-178 \mathrm{~cm}$ with the mean height of $168 \mathrm{~cm}$.

\begin{tabular}{|lc|}
$\begin{array}{l}\text { Table } 1 \text { : ASA physical status of the population. } \\
\text { ASA physical status } \\
\text { ASA I }\end{array}$ & 32 \\
\hline ASA II & 43 \\
ASA III & 15 \\
ASA IV & 10 \\
& \\
\hline Table 2 : Time of onset of Sensory block. \\
Time (min) & Number of Patients \\
\hline $0-5$ & None \\
$5-10$ & 26 \\
$10-15$ & 56 \\
$15-20$ & 12 \\
$20-25$ & 04 \\
$>25$ & 02 \\
\hline
\end{tabular}

$\begin{array}{lc}\begin{array}{l}\text { Table 3: Maximum spread of block } \\ \text { Level of block }\end{array} & \text { Number of patients } \\ \text { T6 } & 4 \\ \text { T8 } & 36 \\ \text { T10 } & 56 \\ \text { T1 } & 22 \\ \text { Patchy block } & 2\end{array}$

The intensity of block was seen with the modified bromage scale where $91 \%$ of patients has bromage scale grade 0 , in a same way $6 \%$ of patients has grade 1 , similarly $4 \%$ of patients has grade 3 and none has grade above it.

The mean duration of surgery was $42 \pm 7.68$ whereas the duration of anesthesia was $90 \pm 12.54$. The SPO2 in all the patients were around $96-100 \%$ throughout the surgery. There were not much fluctuations in hemodynamic status of the patients therefore Heart rate(HR), Blood Pressure(BP), Mean Arterial Pressure(MAP) showed no significance alterations that needed any interventions.

\section{DISCUSSION}

Sicard and Cathelin introduced Caudal epidural block in the year 1901 in France. There were lots of clinical works regarding its use in urological surgery especially in TURP. Kose et al, Yadav et al, Bhattacharya et al has concluded that Caudal epidural block is effective and safe to use in case of TURP. $^{17-19}$ But none of studies regarding its use in ureteroscopic lithotripsy has been performed till date.

The mean duration of surgery in our study was $42 \pm 7.68$ and the mean duration of anesthesia was $90 \pm 12.54$. The study done by Aatif Sheikh Hassan et al had a mean duration of surgery $41.4 \pm 1.29$ minutes whereas duration of anesthesia was not mentioned by his study. ${ }^{13}$

The location of ureteric stone in our study was seen more on the distal ureter in comparison with upper and middle ureter and similar finding was seen with the study done by Ahmed Shelbaia et al where the 89 patients had the lower ureteric stone. $^{14}$

The success of Ureterscopic lithotripsy under local anesthesia was done by various authors like Rittenberg et al, Yalcinkaya et al, and concluded with more than $80 \%$ of clearance of stone. ${ }^{15,16}$ Though our study was done on caudal epidural block, the success of overall calculi free rate was more than $90 \%$. This more percentage of clearance of stone in our study may be due to stone size smaller and stone locations more in the distal ureter.

The time of onset of block was in between 5-20 minutes in $94 \%$ of the patients whereas in $6 \%$ of patients time taken for onset of block was greater than 20 minutes. Regarding the spread of block, the maximum spread of block was at T6 level in $4 \%$ of patients, T8 level in $36 \%$ of patients and T10 level in $56 \%$ of patients. The onset of block, spread of block and intensity of block was similar to the study done previously by Kose et al and yadav et al, though their study was done on transurethral resection of prostrate (TURP). ${ }^{17,18}$

The reason behind the patchy anesthesia in 2 patients in our study may be due to inability to break all the septa that leads to sacral sparing and incomplete sacral nerve root block which was also seen in the study done by Bhattacharyya et al. ${ }^{19}$

In our study all the patient's ureteric lithotripsy could be performed solely under caudal anesthesia except in two patients with patchy anesthesia and two patients with spread of block till T12 level. In these patients surgery could be achieved with the use of intravenous injection Propofol and injection Fentanyl. These patients had a lower ureteric stone and stone size ranging from $5 \mathrm{~mm}-6 \mathrm{~mm}$ which also may be the reason the stone could be removed easily.

In our study none of the patients had Nausea and Vomiting during the procedure. This may be due to less hemodynamic changes leading to decrease in blood pressure rapidly. 
In our study there were no any serious complications which lead to mucosal avulsion or perforation and also there was not a single case that converted to open surgery. Fang yu qiang et al had a similar finding with our study where there was no any mucosal avulsion or perforation and none of their cases converted to open method either. ${ }^{20}$

Regarding the studies comparing the type of anesthesia used in Ureteroscopic lithotripsy (URSL), there are plenty of studies comparing among spinal anesthesia, general anesthesia and local anesthesia by various authors and most of the authors confirmed that regional or general anesthesia could be performed safely and effectively with more or less similar adverse effects. ${ }^{21,22}$ In our study we have performed under caudal epidural anesthesia, a type of regional anesthesia which has less complications than spinal or general anesthesia in patients with more co morbidity and can also be done safely where general or spinal anesthesia is contraindicated.

\section{CONCLUSION}

Ureteroscopic Lithotripsy, a common procedure in urosurgical operation theatre can be carried out with caudal

\section{REFERENCES}

1. Scales CD, Smith AC, Hanley JM, et al. Prevalence of kidney stones in the United States. Eur Urol. 2012;62(1):160-165. DOI: 10.1016/ j.eururo.2012.03.052

2. Netto Junior NR, Claro Jde A, Esteves SC, Andrade EF. Ureteroscopic stone removal in the distal ureter. Why change? J Urol 1997; 157 2081-3. PMID: 9146584

3. Gurbuz ZG, Mimaroglu S, Gurkan L, Oder M, Verim L. Ureteroscopic treatment of multiple distal-ureteral stones. J Endourol 2006; 20 : 1022-4. DOI:10.1089/end.2006.20.1022

4. Dretler SP, Cho G. Semirigid ureteroscopy: A new genre. J Urol 1989;141:1314 18

5. Matlaga BR, Lingeman JE. Surgical management of upper urinary tract calculi. In: Alan JW, Kavoussi LR, Alan WP, Novick AC, Craig AP, editors. Campbell Walsh Urology 10 ed. Vol. 2. Philadelphia: Elsevier Saunders; 2012.p.13756

6. Yalcinkaya F, Topaloglu H, Ozmen E, Unal S. Is general anesthesia necessary for URS in women? Int Urol Nephrol 1996;28:153 6. DOI: $10.1007 /$ bf02550853

7. Bierkens AF, Hendrikx AJ, De La Rosette JJ, Stultiens GN, Beerlage HP, Arends AJ, et al. Treatment of mid and lower ureteric calculi: Extracorporeal shock wave lithotripsy vs. laser ureteroscopy. A comparison of costs, morbidity and effectiveness. Br J Urol 1998; 81:315. DOI:10.1046/j.1464-410x.1998.00510.x

8. Manchikanti L, Cash KA, McManus CD, Pampati V, Smith HS. One-year results of a randomized, double-blind, active controlled trial of fluoroscopic caudal epidural injections with or without steroids in managing chronic discogenic low back pain without disc herniation or radiculitis. Pain Physician. 2011;14:25-36.PMID:21267039

9. Botwin K, Brown LA, Fishman M, Rao S. Fluoroscopically guided caudal epidural steroid injections in degenerative lumbar spine stenosis. Pain Physician. 2007;10:547-58. PMID:17660853

10. Kiribayashi M, Inagaki Y, Nishimura Y, Yamasaki K, Takahashi S, Ueda K. Caudal blockade shortens the time to walking exercise in elderly patients following low back surgery. J Anesth. 2010;24:192-6. DOI:10.1007/s00540-009-0840-6

11. Kita T, Maki N, Song YS, Arai F, Nakai T. Caudal epidural anesthesia administered intraoperatively provides for effective postoperative analgesia after total hip arthroplasty. J Clin Anesth. 2007;19:204-8. PMID:17531729 epidural block preferably for lower ureteric stones of sizes less than $15 \mathrm{~mm}$ as it provides adequate satisfactory anesthesia with sensory block up to T10 if administered by an experienced Anesthesiologist.

\section{LIMITATIONS OF THE STUDY}

The sample size could be larger. The caudal epidural block if compared with spinal and general anesthesia the study would be more effective in knowing the better options among these three techniques.

\section{ACKNOWLEDGEMENTS}

A special thanks to all my patients who participated in this study. Also thanks to all my residents and colleagues who helped me during this study directly or indirectly.

\section{CONFLICT OF INTEREST}

None

\section{FINANCIAL DISCLOSURE}

None

12. Wong SY, Li JY, Chen C, Tseng CH, Liou SC, Tsai SC, et al.Caudal epidural block for minor gynecologic procedures in outpatient surgery.Chang Gung Med J. 2004;27:116-21. PMID:15095956

13. Aatif sheikh Hassan, Salman Al Khalid, Syed zafar Zaidi: Ureteroscopy under spinal Versus General Anesthesia: Morbidity and stone Clearance. Journal of College of Physicians and Surgeons Pakistan 2008, Vol.18(3):168-71.

14. Ahmed Shelbaia, Sherif Abd ELRahman, Ali Hussein. Ureteroscopic Lithotripsy Under Local Anesthesia and Without Intravenous Analgesia in Adults: Analysis of the Effectiveness and Patient Tolerability of About 100 Patients. UroToday Int J. 2011 Dec;4(6): art77. DOI: 10.3834/uij.1944-5784.2011.12.10

15. Rittenberg $\mathrm{MH}$, Ellis DJ, Bagley DH. Ureteroscopy under local anesthesia. Urol.1987;30(5):475-6. PMID:3672684

16. Yalcinkaya F, Topaloglu H, Ozmen E, Unal S. Is general anaesthesia necessary for URS in women? Int. Urol. Nephro.1996;28(2):153-6. DOI:10.1007/bf02550853

17. Kose EA, Ozturk A, Ates G, Apan A. Caudal epidural block for elderly patients who have limited cardiac reserve. Turk J Med Sci 2012;42: 1347-51. DOI:10.3906/sag-1201-3

18. Yadav SS, Gupta S, Choudhary B. A Clinical study of Caudal epidural anaesthesia for transurethral resection of prostate. JEMDS2015;4: 10309-20. DOI: $10.14260 /$ jemds/2015/1485

19. Bhattacharya S, Bisai S, Biswas H, Tiwary MK, Mallik S, Saha SM. Regional anesthesia in transurethral resection of prostate(TURP) surgery. A comparative study between saddle block and subarachnoid block. Saudi J Anaesth 2015;9:268-71. PMID:26240544

20. Fang You-qiang, Qiu Jian-guang, Wang De-juan, Zhan Hai-lun, Situ Jie. Comparative study on ureteroscopic lithotripsy and laparoscopic ureterolithotomy for treatment of unilateral upper ureteral stones. Acta Cir. Bras. [Internet]. 2012 Mar [cited 2020 Jan 10] ; 27( 3 ): 266-270. DOI: 10.1590/S0102-86502012000300011.

21. Iroglu C, Saporta L. Transurethral utersoscopy: Is local anesthesia with intravenous sedation sufficiently effective and safe? Eur Urol 1997;31:36-9. PMID:9032532

22. Osking DH, Smith WE, McColm SE. A comparison of extracorporeal shock wave lithotripsy and ureteroscopy under intravenous sedation for the management of distal ureteric calculi. Can J urol 2003;10: 1780-4. DOI: 10.1590/S1677-55382006000600006 